\title{
Efeitos de sentidos de tipos dêiticos
}

\author{
Mônica Magalhães Cavalcante* \\ Mayara Arruda Martins ${ }^{* *}$
}

Resumo: Neste artigo, investigamos aspectos argumentativos da dêixis, examinando efeitos de sentido gerados pelo uso desse processo referencial. Quanto à argumentação, baseamo-nos em Cavalcante (2018) e em Amossy (2011) para considerar a argumentatividade presente em todo texto. Quanto à dêixis, baseamo-nos, sobretudo, nas classificações e caracterizações feitas por Cavalcante (2000) e Martins (2019). Selecionamos textos de gêneros diversos para analisar efeitos de sentido gerados por tipos dêiticos presentes em Martins (2019), como recorte metodológico. Hipotetizamos, portanto, que a dêixis colabora com a orientação argumentativa, pois funciona como ferramenta para os interlocutores atingirem efeitos de sentido de influência sobre o outro. Palavras-chave: Dêixis. Efeitos de sentido. Contexto. Argumentação.

Abstract: In this article, we investigate argumentative aspects of deixis, examining effects of meaning generated by the use of this referential process. With respect to argumentation, we draw on Cavalcante (2018) and Amossy (2011) and consider the argumentativity present in every text. With respect to deixis, we mainly draw on the classifications and characterizations built by Cavalcante (2000) and Martins (2019). Our methodology approach was to select texts to analyse effects of meaning generated by deictic types present in Martins (2019). We hypothesize deixis collaborates with the argumentative orientation, since it works as a tool of influence upon the other.

Keywords: Deixis. Effect of meaning. Context. Argumentation.

Resumé: Dans cet article, nous investigons des aspects argumentatives de la deixis, examinant des effets de sens générés par l'usage de ce proces référentiel. Par rapport à l'argumentation, nous utilisons Cavalcante (2018) et Amossy (2011) afin de considérer l'argumentativité presente en touts les textes. Par rapport la deixis, nous utilisons, surtout, les classifications et caractérisations conçues par Cavalcante (2000) et Martins (2019). Nous avons selectionné des textes afin d'analiser des effets de sens générés par types deictiques presents en Martins (2019). Comme hypothèse, nous disons que la deixis collabore avec l'orientation argumentative, parce qu'elle fonctionne comme un outil d'influence sur l'autre.

Mots-clés: Deixis. Effets de sens. Contexte. Argumentation.

\footnotetext{
${ }^{*}$ Professora do Departamento de Letras Vernáculas e do Programa de Pós-Graduação em Linguística da Universidade Federal do Ceará (UFC). Doutora em Linguística pela Universidade Federal de Pernambuco (UFPE). Líder do Grupo Protexto (CNPq/UFC). http://orcid.org/oooo-0002-5561-3993

${ }^{* *}$ Doutoranda no Programa de Pós-Graduação em Linguística da Universidade Federal do Ceará (UFC). http://orcid.org/0000-0001-5673-0780
}

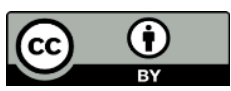

Este artigo está licenciado sob forma de uma licença Creative Commons Atribuição 4.0 Internacional, que permite uso irrestrito, distribuição e reprodução em qualquer meio, desde que a publicação original seja corretamente citada. https://creativecommons.org/licenses/by/4.0/deed.pt_BR. 


\section{Considerações iniciais}

O presente artigo faz parte de uma pesquisa de doutorado que objetiva investigar os aspectos argumentativos do processo referencial dêitico. Concordando com Cavalcante (2018) que todo texto é argumentativo, investigamos de que modo a dêixis estabelece efeitos de sentido que visam à argumentação nos textos, embora, muitas vezes de forma velada, pelo simples uso de marcas dêiticas pessoais.

O potencial argumentativo das formas dêiticas se justifica por seu caráter metadiscursivo (HYLAND, 2005), em que o locutor se instaura na interação ao mesmo tempo que busca atingir seu auditório através do engajamento, muitas vezes marcado formalmente. Os dêiticos, assim, se prestam à tentativa de influência do outro ou do terceiro, sendo um recurso fundamental que a própria língua disponibiliza para esse fim, de acordo com Amossy (2011).

Dos oito tipos dêiticos elencados por Martins (2019) em sua dissertação, faremos um recorte metodológico neste trabalho de apenas quatro - os mais conhecidos e mais comumente trabalhados por pesquisadores da área: o pessoal, o social, o espacial e o temporal. Analisamos textos de diversos gêneros, pois objetivamos verificar o efeito criado a partir dos usos dos dêiticos nos diversos tipos de situação interativa, considerando o contexto de produção, de recepção e de circulação do gênero envolvido e os papéis sociais dos participantes em dado entorno social, visando à orientação argumentativa.

\section{A identificação e o engajamento dos dêiticos pessoais}

A utilização dos dêiticos pessoais ocorre para transmitir muitos efeitos além de identificar os interlocutores da situação comunicativa. Os usos de dêiticos pessoais 
fazem com que os interlocutores possam manifestar sua adesão (ou não) a determinados posicionamentos. Além disso, podem servir para engajar pares comuns, ou para buscar a identificação de leitores/interlocutores, entre outros. Vejamos o exemplo a seguir para discutir um efeito de sentido criado pela utilização desse tipo dêitico.

\section{Exemplo 1}

\section{Uma boa mulher permanece ao lado de um homem, mesmo que ele minta, traía e engane. Essa mulher é a mãe dele, nós não...}

Fonte:

https://me.me/i/diferentona-diferentonabr-uma-boa-mulher-permanece-ao-lado-de-um1b95866fbgae4e68b4b0465706f2c3b8 Acesso em: 26 jan. 2020.

O texto acima é recorrente no ambiente da internet e está disponível na página Diferentona, embora apareça também compartilhado em outras páginas. Chamaremos, para os propósitos deste trabalho, de post da página Diferentona, sem aprofundar as questões relativas à caracterização dos gêneros, pois o que pretendemos é verificar o efeito que o uso do dêitico pode ter na construção das redes referenciais do texto em seu universo contextual.

Nessa postagem, há uma sátira ao tipo de mulher ideal amplamente compartilhado e socialmente aceito, sobretudo até os anos 2000: aquela mulher que tudo aceita, que não reclama, não impõe seus próprios interesses, que se encaixa no estereótipo de Amélia. O texto apresenta, portanto, uma quebra de expectativa, ao recategorizar essa mulher como a figura da mãe, mostrando, assim, que o estereótipo da 
mulher do nosso tempo mudou bastante: a mulher faz questão de ser vista como decidida e capaz de sair de situações desconfortáveis. Essa recategorização faz o texto progredir, modificando o referente que estava sendo construído, tal como afirmam Cavalcante e Brito (2016):

...o fenômeno da recategorização compõe a dinâmica natural de retomada anafórica, pela qual os referentes, ao mesmo tempo que se mantêm no texto por algum tipo de associação, também evoluem em diferentes proporções, em proveito da progressão temática. (CAVALCANTE, BRITO, 2016, p. 119)

Em termos dêiticos, podemos acrescentar que a primeira pessoa atualiza o participante-locutor, que se coloca no lugar de eu. Esse colocar-se no lugar ocorre pela explicitação do pronome nós. Pode ser exatamente este o principal efeito e o principal objetivo de postagens dessa natureza, que têm ampla recorrência e compartilhamento: apelar para que o interlocutor se identifique com a situação retratada. Ao gerar essa identificação, os sujeitos se colocam no lugar de autores do texto, aderem à opinião exposta e compartilham. Ocorre, portanto, inicialmente, um processo de engajamento do leitor, que passa, em seguida, a se posicionar através da postagem.

Cavalcante (2000, p.32) afirma que o uso de marcas gramaticalmente convencionadas serve justamente para dar mais saliência a tudo o que representa o eu, a marca por excelência da subjetividade, como num convite ao interlocutor para que se veja no mesmo contexto criado, na mesma situação comunicativa simulada. É por identificação com a situação que o interlocutor se vê engajado, o que evidencia um dos usos metadiscursivos dos dêiticos.

A seguir, apresentamos de que modo o uso de outro tipo de dêiticos, os sociais, interferem na orientação argumentativa dos textos.

As evidências de polidez linguística e de preservação de face dos dêiticos sociais 
Os dêiticos sociais não são escolhas aleatórias para se reportar ao outro. Os modos de se referir ao outro podem evidenciar estratégias de preservação de face ou de exposição da face negativa do outro, indicando, portanto, uma estratégia de polidez.

As formas dêiticas sociais são recursos que indicam tipos de relação social entre os interlocutores. Kerbrat-Orecchioni (2006) inclui na noção de polidez todos os aspectos interacionais regidos por regras sociais que busquem a preservar as relações interpessoais, dentre as quais destaca as formas de tratamento (pronominais e nominais):

As formas de tratamento, evidentemente, devem ser mencionadas logo de início, porque são os marcadores mais manifestos da relação, quer se trate:

- do pronome de tratamento: o "você" sendo o símbolo, por excelência da familiaridade, em oposição ao tratamento "senhor(a)", que marca o distanciamento;

- ou dos nomes de tratamento: não é a mesma coisa designar seu interlocutor por "caro colega", "senhor", "Silva”, "José”, "Zé”, "amigo", "querido"... (KERBRAT-ORECCHIONI, 2006, p. 66)

Embora não estejamos restringindo a noção de cortesia ao emprego de formas de polidez linguística, estamos limitando a análise deste aspecto, neste trabalho, ao uso de marcas dêiticas, a fim de corroborar a afirmação da autora de que "a polidez é um conjunto de procedimentos que o falante utiliza para poupar ou valorizar seu parceiro de interação" (KERBRAT-ORECCHIONI, 2006, p. 94). Dentre esses procedimentos disponíveis para os falantes, estão os dêiticos sociais, como podemos comprovar pelos exemplos a seguir: 
Exemplo 2

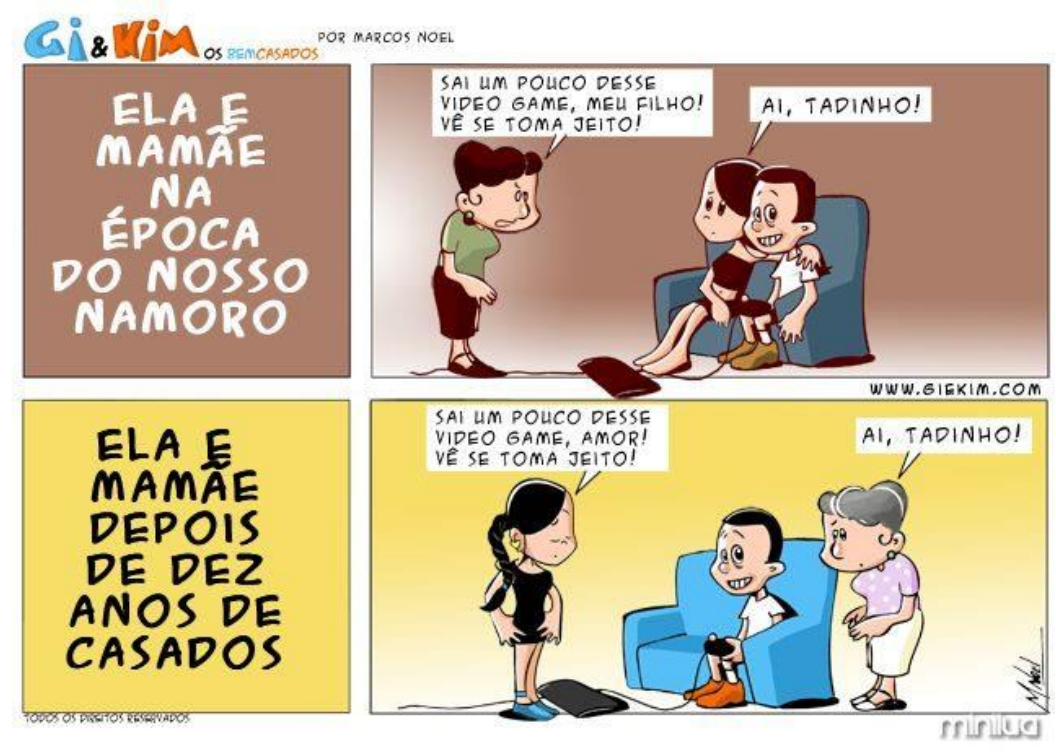

Fonte:

https://www.google.com/search?q=tirinha+engra\%C3\%A7ada+star+wars\&tbm=isch\&ved=2ahUKEwj hc GvqfrnAhUmBLkGHU77 $\mathrm{Cy}_{4} \mathrm{Q}_{2}-$

cCegQIABAA\&oq=tirinha+engra\% $\mathrm{C}_{3} \% \mathrm{~A} 7 \mathrm{ada}+$ star+wars\&gs $\mathrm{l}=\mathrm{img} .3 \ldots 95662.102757 . .103392 \ldots 3.0 . .0 .149 .28$ 05.0j21..............gws-wiz-img........ojoi5izojoi8izojoizo.AXPgHgb2h7M\&ei=-zZcXr-

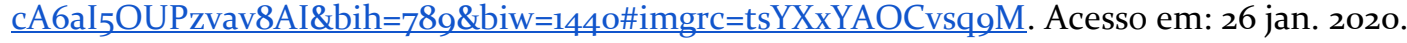

No exemplo acima, a relação familiar entre os interlocutores é apresentada através das formas "meu filho" (mãe e filho) e "amor" (cônjuge). Embora a situação pareça exatamente a mesma, a relação entre as personagens é modificada através da inversão de papéis entre aquela que reclama e aquela que defende. Caso a tirinha não utilizasse o recurso dos dêiticos sociais, que marcam o parentesco entre as personagens, a compreensão se daria por outros recursos, como a explicação inicial do quadrinho e o recurso visual (aparência das personagens, expressões faciais e construção da cena). Não queremos afirmar aqui que esses elementos não contribuem para a construção dos sentidos do texto, mas reiteramos que os dêiticos sociais utilizados auxiliam na construção da coerência.

As relações sociais presentes no exemplo 2 também encontram respaldo em Bakhtin (1990), que enfatizou o aspecto social da enunciação no que se refere às relações entre os interlocutores que nela estão inseridos: 
Com efeito, a enunciação é o produto da interação de dois indivíduos socialmente organizados e, mesmo que não haja um interlocutor real, este pode ser substituído pelo representante médio do grupo social ao qual pertence o locutor. A palavra dirige-se a um interlocutor: variará se tratar de uma pessoa do mesmo grupo social ou não, se esta for inferior ou superior na hierarquia social, se estiver ligada ao locutor por laços sociais mais ou menos estreitos (pai, mãe, marido, etc.) (BAKHTIN, 1990, p. 112).

Aceitamos inteiramente esse pressuposto, uma vez que os papéis sociais desempenhados pelos interlocutores na situação de enunciação estão sempre presentes, ainda que não estejam marcados por formas dêiticas. Como explicamos no exemplo anterior, mesmo com a ausência dos dêiticos sociais, ainda seria possível inferir essas relações através de outros recursos utilizados no texto. $\mathrm{O}$ exemplo 3 também confirma o que estamos defendendo:

\section{Exemplo 3}

- COELCE Natália boa tarde por gentileza com quem eu falo?

- Minha querida não tem negócio de boa tarde não o seguinte é esse, estou com as duas últimas faturas pagas, da minha luz e veio um hômi que num tem o que fazer qu'eu acho qu'ele num tem o que fazer não e corta minha luz eu tenho criança!

- Senhora tenha calma, é.. senh..

- CALMA É O C@CETE! Anote os números que tem aqui na minha fatura paga!

- Calma senhora! Calma!

- Minha filha você ainda tá pedindo calma? Anote, eu não posso ficar sem energia não, porque eu tenho criança! Certo? Inclusive, tem uma senhora aqui que é doente...

- Calma senhora.

- ...é dependente de energia.

- Mas a senhora...

- Anote o número!

- A senhora...

- Três, quatro, meia, sete...

- Deixa eu falar senhora?

- ... oito, oito, sete, três...

- Não, eu não estou anotando, mas se você tiver um pouquinho de calma eu vou estar anotando.

- MINHA FILHA...

- Tenha calma, pra mim fazer sua nova religação senhora.

- Anote o número!

- Perainda, olha o respeito pela gente aqui. A gente não tem essas irresponsabilidades pelo seu corte da sua residência... - Minha filha, mas eu não posso esperar que eu sou ocupada, eu tenho o que fazer, eu não posso ficar perdendo tempo no telefone não.

- Calma senhora, fale direito comigo porque eu não tenho nada a ver com o seu cooorte da sua residência.

- Mas tá pago minha querida!

- Sim meu amor, tenha calma, respire fundo que agora eu vou fazer su...

- Não quero saber, anote o número! Cê ainda tá discutindo? Você é pra receber ordens. 
- (risos) senhora me informe aí seu nome completo por gentileza!

- Você é subordinada! Anote o número!

- Não, a gente não quer número agora, queremos só o seu nome completo!

- MARIA IZOLDA DA SILVA (risos)

- Senhora? (risos)

- Minha filha você tá me levando a pagode mesmo é? (risos) isso é uma Porra! A gente paga as coisas direito aí uma praga dessa (risos).

- O que diabo é Izolda? (risos)

Fonte:

https:/pandlr.com/forum/nro-pan/forum/topic/off-minha-querida-tem-negocio-de-boa-tarde-naoseguinte-e-esse/?cache=1. Acesso em: 26 jan. 2020.

O exemplo 3, que viralizou como o "trote da Coelce", apresenta vários dêiticos sociais com alguns efeitos diferentes do efeito gerado pelo uso desse tipo dêitico no exemplo 2. As formas lexicais escolhidas pelos interlocutores e utilizadas na situação para se referir aos pares revelam uma primeira pessoa que assume um papel social dentro da interação. Isso se percebe, dentre outras evidências, pelo fato de a atendente escolher uma forma de maior distanciamento, isto é, maior grau de polidez em relação à interlocutora (senhora) ao invés de simplesmente tratá-la por "você". Tal escolha já marca uma posição de respeito, uma enunciadora que traz outras vozes para dentro de seu dizer - a voz da empresa. Isso se dá porque são os sujeitos envolvidos nas situações que escolhem as palavras que usarão para se reportar ao outro, e essas decisões são associadas às coerções que os próprios gêneros apresentam para essas escolhas (uma atendente de telemarketing não poderia tratar uma cliente de forma descortês).

A cliente, por outro lado, se vale de formas como "minha querida" e "minha filha", que poderiam expressar uma aproximação entre as interlocutoras ou funcionar como uma forma de chamamento afetiva. No entanto, pelo contexto, percebemos que esses usos evidenciam o teor irônico presente nas falas da cliente, o que acontece também na fala da atendente no fim do diálogo, com o emprego da expressão "meu amor".

Demonstramos, assim, que, em muitos casos, nem sempre a utilização de uma forma convencionalmente polida suaviza o dizer. Ele pode se prestar ao efeito contrário: gerar uma ironia. Apesar de parecer uma simples forma para evocar o outro, é somente 
a partir do contexto que podemos saber se se trata de um uso mais agressivo, mais afetivo, mais irônico, entre outros.

Essas escolhas dos interlocutores pontuam trilhas de sentido que levam à orientação argumentativa que se quer sustentar, já marcando, em muitos casos, pontos de vista, posicionamentos, ideologias e estereótipos.

A expressão dos pontos de vista dos interlocutores não está restrita a um só tipo dêitico. A seguir, demonstraremos de que modo os dêiticos espaciais revelam posicionamentos afetivos.

\section{A afetividade dos dêiticos espaciais}

Os dêiticos espaciais nem sempre são utilizados para indicar uma localização física na construção da referência. Eles podem marcar o posicionamento argumentativo sobre determinado objeto ou situação.

Valemo-nos de Cavalcante (2000) para afirmar que os dêiticos espaciais criam um efeito de "realidade" ao situarem o locutor dentro de um campo mostrativo. A localização dos referentes em relação aos interlocutores pode graduar os traços de emotividade: quanto mais tomarem como ponto de referência o locutor, mais próximos de sua afetividade estarão. Observemos, então, o exemplo a seguir:

\section{Exemplo 4}

Um sujeito estava numa situação financeira desesperadora. Resolveu então apelar: escreveu uma carta destinada a Deus, pedindo 100 reais, e colocou na caixa do correio.

Durante a triagem, no correio, os funcionários viram o nome do destinatário e, curiosos, resolveram abrir a carta. Ficaram com tanta pena que um deles teve uma ideia: - Vamos fazer uma vaquinha aqui em nosso setor para ajudar este coitado. Após arrecadarem o dinheiro, colocaram num envelope e o enviaram. Quando recebeu a carta, o coitado abriu e viu que tinha 80 reais dentro. De pronto, escreveu outra carta para Deus, dizendo: - Meu Deus, muito obrigado por me atender. Uma pena que aqueles funcionários safados do correio passaram a mão em 20 pratas!

Fonte: https://www.piadasnet.com/piada618diversas.htm. Acesso em: 29 jan. 2020. 
O locutor utiliza a forma "aqueles" para se referir aos funcionários do correio, uma vez que eles estão fisicamente distantes dele, além de apelar para a memória e demonstrar uma distância afetiva em relação a eles, por achar que lhe roubaram 20 pratas.

O funcionário que propõe a ideia e emite a fala, por outro lado, demonstra o caráter afetivo entre ele e o homem que escreveu a carta. Isso é identificável a partir do uso do demonstrativo de primeira pessoa (este) para se referir ao coitado. $\mathrm{O}$ uso desse tipo de demonstrativo poderia não exercer esse efeito, caso o homem estivesse fisicamente próximo a quem proferiu a frase. No entanto, mesmo estando distante, ainda parece "presente", pois, ao utilizar "este coitado", o funcionário demonstra uma aproximação entre eles. Afirmamos isso tomando por base Cavalcante (2000), que discute o uso de demonstrativos, enfatizando seu caráter afetivo ou depreciativo:

A forma demonstrativa tem, portanto, a capacidade de dosar a proximidade/distância não apenas física, mas, às vezes, "afetiva" do referente em relação ao ponto de vista do emissor. E as regras, no plano da afetividade, são mais fluidas do que se pode suspeitar. O mesmo traço afetivo (...) pode, por exemplo, promover a seleção do pronome de segunda pessoa (em vez do de primeira), se a intenção for claramente depreciativa. (CAVALCANTE, 20oo, p. 107)

Procuramos mostrar o efeito de sentido de afetividade atrelado ao uso de dêiticos espaciais. Na próxima seção, apresentamos a discussão dos efeitos de sentido da dêixis a partir da demonstração dos dêiticos temporais.

\section{A circularidade e a persuasão dos dêiticos temporais}


Os dêiticos temporais são utilizados essencialmente para se referir ao momento em relação ao tempo de enunciação, isto é, o agora, o hoje. No entanto, alguns textos geram efeitos de circularidade ou efemeridade temporal, visando à persuasão. Para discutirmos sobre esses efeitos de sentido dos dêiticos temporais, apresentamos os exemplos a seguir:

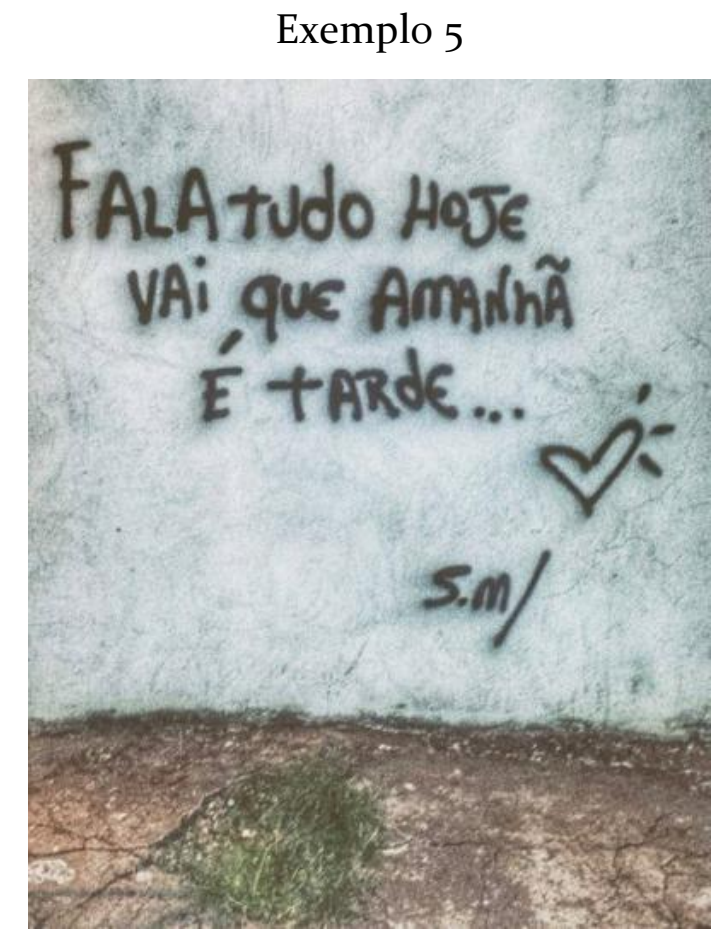

Fonte: https://pt-br.facebook.com/ComAfeto/posts/1434559353311793/. Acesso em: 30 jan. 2020.

As formas "hoje" e "amanhã", presentes no exemplo 5, são consideradas dêiticos temporais por necessitarem da instauração de uma origo na situação enunciativa. Deste modo, faz-se necessário um "eu" que atualize um "hoje" e, em decorrência dessa marca temporal, um “amanhã”. Esse uso pode parecer simples ou desproposital, mas os efeitos alcançados através desse recurso dêitico são diversos. Nesse exemplo 5, o uso dos dêiticos temporais acaba por criar uma reflexão acerca de um amanhã que pode não chegar. Alguns gêneros, como textos motivacionais e de autoajuda também se valem, muitas vezes, desse uso para enfatizar a importância de "viver o hoje”, intensamente, 
tendo em vista a efemeridade do tempo, o que reforça a ideia de que é necessário viver o presente. O amanhã, nesse caso, ganha o sentido de futuridade de modo geral.

Esse tipo de uso também é bastante presente na prática de coaching, típica dos ensinamentos de coaches. Essa prática, muito recorrente, tem sido cada vez mais criticada, sobretudo, pela repetição de padrões e de "frases de impacto".

Com a intenção de satirizar a linguagem de coaches e gerar o humor, foi criada a página @coachdefracassos, que se vale do recurso de imitação de estilo, como podemos perceber no exemplo 6, abaixo:

\section{Exemplo 6}

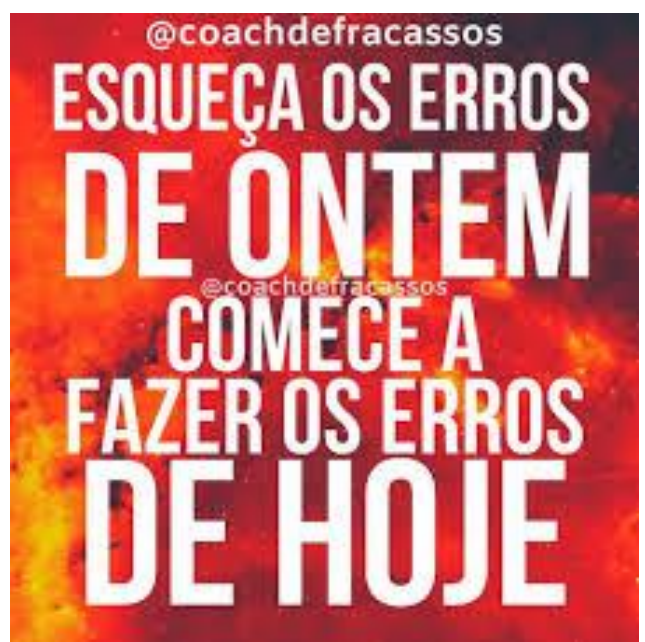

Fonte:

https://www.facebook.com/coachingdefracassos/photos/a.1838690292835245/2673453539358912/?type=3 \&comment id=2674258389278427. Acesso em: 30 jan. 2020.

No exemplo 6, temos uma postagem criada a partir do padrão de textos utilizados por coaches. Do mesmo modo do exemplo 5, analisando o texto pelas formas linguísticas, essa postagem utiliza dêiticos temporais, como "ontem" e "hoje". Porém, o sentido que essas formas geram é diferente, pois aparece carregada de humor, ao invés de levarem à reflexão. 
Esse humor é gerado não somente pela utilização dos dêiticos, mas, sobretudo, pelo novo contexto de produção, circulação e recepção desse gênero, reproduzido para fim humorístico, numa imitação de estilo, estando, assim, em relação de oposição à esfera de discurso de coaching.

Ainda em oposição ao "amanhã" do exemplo anterior, que indica futuridade, o “ontem" desse exemplo indica muito mais que "o dia que antecede o hoje”, pois ganha sentido de tempo passado de modo geral.

Seja qual for o efeito de sentido que o dêitico agregue ao texto, destacamos a relevância da utilização dos dêiticos para a orientação argumentativa dos textos. Desse modo, ampliamos os estudos da área acerca desse objeto, enfatizando que a dêixis deve ser analisada em contexto.

\section{Considerações finais}

Neste trabalho, analisamos quatro tipos dêiticos (pessoal, social, espacial e temporal), discutindo os sentidos que as formas dêiticas podem assumir como ferramentas de que os interlocutores podem se valer para contribuir com a orientação argumentativa dos textos.

Para que fosse possível chegar a alguns dos efeitos de sentido dos textos, ressaltamos a necessidade de se considerar alguns critérios, como o contexto de produção, de recepção e de circulação do gênero envolvido, bem como os papéis sociais dos participantes dentro dos contextos e das interações.

Neste trabalho, como recorte, apresentamos alguns dos efeitos de sentido dos tipos selecionados, como: os dêiticos pessoais geram identificação entre os interlocutores ou entre o texto e seu interlocutor, além de servir de recurso para engajálos; os dêiticos sociais são utilizados como recursos para evidenciar a relação entre os interlocutores, atuando como estratégias de polidez; os dêiticos espaciais, em determinados contextos de uso, podem demonstrar a afetividade (positiva ou negativa) entre interlocutores ou entre interlocutores e referentes; os dêiticos temporais, tanto 
para fins de humor como para fins de reflexão, demonstram efeito de circularidade temporal e de persuasão.

Sabemos, no entanto, que as pesquisas sobre as colaborações da dêixis, assim como as dos outros processos referenciais, para a construção da argumentação nos textos das mais diversas semioses, ainda são escassas e precisam de aprofundamento. Por isso, ressaltamos a importância de se desenvolver pesquisas na área, atentando para os vários modos de construção de referentes, para além de meras formas linguísticas, e para os diversos modos de interação e de relação entre os interlocutores nas situações comunicativas.

\section{Referências}

AMOSSY, R. Argumentação e Análise do Discurso: perspectivas teóricas e recortes disciplinares. Trad. Eduardo Lopes Piris e Moisés Olímpio Ferreira. EIDEA - Revista Eletrônica de Estudos Integrados em Discurso e Argumentação, Ilhéus, n. 1, p. 129-144, nov. 2011.

BAKHTIN, M. (Volochinov). Marxismo e Filosofia da Linguagem. Tradução de Michel Lahud e Yara Frateschi Vieira. 5. ed. São Paulo: Hucitec, 1990.

CAVALCANTE, M. M. Expressões indiciais em contextos de uso: por uma caracterização dos dêiticos discursivos. Recife, 205p. Tese /Doutorado em Lingüística/ - Universidade Federal de Pernambuco (UFPE). 2000.

. Por uma análise argumentativa na Linguística Textual. 2018. In: VITALE, María

Alejandra et al. Estudios sobre discurso y argumentación. Coimbra: Grácio Editor, 2019. p. 319-338.

; BRITO, M. A. P. O caráter naturalmente recategorizador das anáforas. In: Estudos do discurso: caminhos e tendências. São Paulo: Editora Paulistana, 2016.

HYLAND, K. Metadiscourse: Exploring Interaction in Writing. Continuum: London and New York, 2005. 
KERBRAT-ORECCHIONI, C. Análise da conversação: princípios e métodos. Tradução Carlos Piovezani Filho. São Paulo: Parábola, 2006

MARTINS, M. A. A caracterização dos tipos dêiticos como processos referenciais. 142f. Mestrado em Linguística. Fortaleza: Universidade Federal do Ceará. 2019.

Recebido em o8/03/2020. Aprovado em 31/05/2020. 